\title{
A new method for nocturnal aerosol measurements with a lunar photometer prototype
}

\author{
A. Barreto ${ }^{1}$, E. Cuevas ${ }^{1}$, B. Damiri ${ }^{2}$, C. Guirado ${ }^{1,3,4}$, T. Berkoff ${ }^{5}$, A. J. Berjón ${ }^{1}$, Y. Hernández ${ }^{1}$, F. Almansa ${ }^{1}$, and \\ M. Gil ${ }^{6}$ \\ ${ }^{1}$ Izaña Atmospheric Research Center, Meteorological State Agency of Spain (AEMET), Izaña, Spain \\ ${ }^{2}$ Cimel Electronique, Paris, France \\ ${ }^{3}$ Institute of Environmental Assessment and Water Research, Spanish National Research Council (CSIC), Barcelona, Spain \\ ${ }^{4}$ Atmospheric Optics Group, Valladolid University (GOA-UVA), Valladolid, Spain \\ ${ }^{5}$ University of Maryland Baltimore County, Baltimore, Maryland, USA \\ ${ }^{6}$ Instrumentation and Atmospheric Research Department, National Institute for Aerospace Technology (INTA), Madrid, Spain
}

Correspondence to: E. Cuevas (ecuevasa@aemet.es)

Received: 23 July 2012 - Published in Atmos. Meas. Tech. Discuss.: 15 August 2012

Revised: 14 January 2013 - Accepted: 15 January 2013 - Published: 5 March 2013

\begin{abstract}
This paper presents the preliminary results of nocturnal Aerosol Optical Depth $\left(\tau_{\mathrm{a}}\right)$ and Angström Exponent $(\alpha)$ obtained from a new lunar photometer prototype, trade name Cimel CE-318U. Due to the variation of the moon's illumination inherent to the lunar cycle, the typical Langleyplot Method used in solar photometry to calibrate these instruments cannot be applied. In this paper, we propose three different methods to carry out the lunar-photometer calibration. In order to validate the results, we have selected three events which encompass seven nights and ten days under different atmospheric conditions, including several saharan dust intrusions episodes. Method\#1 is introduced in this work as a modification of the usual Langley Method. This technique, called Lunar-Langley Method, requires the extraterrestrial irradiances from a lunar irradiance model, providing similar accuracies on $\tau_{\mathrm{a}}$ to those of AERONET $( \pm 0.01-$ 0.02 ). It makes comparable daytime and nighttime measurements. Method\#2 consists of transferring the current calibration from a master used by sunphotometers. Its results are again within the limit of accuracy expected for the instrument. Method\#3 uses an integrating sphere and the methodology proposed by Li et al. (2008) to determine sky calibration coefficients $\left(C_{j}\right)$ and the instrument's solid angle fieldof-view $(\Omega)$, respectively. We observe significant $\tau_{\mathrm{a}}$ differences between Method\#1 and \#3 (up to 0.07), which might be attributed to the errors propagation in Method\#3. The good results obtained from the comparison against a second $\mathrm{CE}$ -
\end{abstract}

318U prototype, and against daytime data from a Precision Filter Radiometer (PFR), constitute a valuable assessment of CE-318U performance. Results of $\alpha$ and its spectral variation $(\delta \alpha)$ show good agreement between daytime and nighttime, being able to identify the aerosol properties associated with each event.

\section{Introduction}

Atmospheric aerosols are known to impact the climate evolution, but they still represent one of the largest uncertainties in climate change studies (IPCC, 2007). The high uncertainty associated with the role played by aerosols in radiative forcing on a global scale makes it necessary to obtain a global ground-based aerosol climatology. In this sense, the Aerosol Robotic Network (AERONET) is nowadays one of the most powerful worldwide tool (Holben et al., 1998). Aerosol Optical Depth $\left(\tau_{\mathrm{a}}\right)$ at a certain wavelength is the standard parameter measured by sunphotometers such as those operating in AERONET. Spectral dependence of $\tau_{\mathrm{a}}$ is mainly driven by the scattering efficiency and can be expressed by means of the classical Angström's equation (Angström, 1929). In the solar spectrum, the Angström exponent $(\alpha)$ is a good indicator of the dominant size of the atmospheric particles. $\tau_{\mathrm{a}}$ and $\alpha$ data obtained from AERONET stations are used to provide independent and trustable validation to satellite-based 
aerosols products and to regional and global aerosol/dust models. However, the lack of nighttime aerosol observations introduces some uncertainties in column aerosol estimations. Nighttime $\tau_{\mathrm{a}}$ is a necessary parameter to derive a continuous sequence of total column aerosol information which is of considerable importance for monitoring aerosol transport, for high latitude locations, given the extended periods of darkness during winter, to study the effect of aerosol particles on cloud lifetime and coverage during the night, and for detecting massive aerosol outbreaks at night (Zhang et al., 2008).

Ground or spaceborne lidar observations have the capability of detecting atmospheric column aerosols at night. However, its spatial coverage is limited and the $\tau_{\mathrm{a}}$ observations can no longer constrain the extinction solution from the backscattering observations (Zhang et al., 2008). Passive sensors for $\tau_{\mathrm{a}}$ measurements at night must solve the problem of the low incoming energy from the nocturnal celestial bodies, which emit in a range of $10^{-5}-10^{-6}$ the sun's energy in the case of the moon, and five orders of magnitude less for the brightest star in the sky, Sirius. On one hand, stellar photometers are proven to be more effective in determining $\tau_{\mathrm{a}}$ at nighttime than lunar photometers. However, the complexity of the large-aperture instrumentation needed to capture the low levels of incoming energy from the stars limits the use of stellar photometers and their implementation in standardised regional or global networks. On the other hand, the relatively high irradiance from the moon provides the possibility of using common-aperture photometers to retrieve aerosol properties at night. Nevertheless the moon can be considered a solar diffuser with an exceptional stability, although the apparent brightness of this celestial body changes continuously with the lunar viewing geometry, such as the lunar phase or the libration angles, and due to the non-lambertian reflectance properties of its surface. As Herber et al. (2002) suggested, the nocturnal calibration in lunar photometry is an important obstacle to overcome, because it is not stable for longer than 1 day and, therefore, the typical Langley procedure must be used for every nocturnal measurement. This problem was tackled by Berkoff et al. (2011) by considering a lunar irradiance model which explicitly accounts for the effects of phase, the spatial variegation of the lunar surface, the changes in the hemisphere of the moon presented to an observer (the lunar librations) and the strong backscatter enhancement at low phase angles (the so-called "opposition effect") (Kieffer and Stone, 2005). This empirical model, known as ROLO (RObotic Lunar Observatory), was developed at the United States Geological Survey (USGS) as a NASA-funded project in support of the Earth Observing System (EOS) programme. ROLO enables using the moon as a radiometric calibration source for onorbit calibration of Earth observing satellites by means of a lunar spectral irradiance model that was developed from extensive telescopic observations acquired over more than $8 \mathrm{yr}$ (Kieffer and Stone, 2005). Kieffer and Stone (2005) found band-average residuals less than $1 \%$ by fitting thousands of
ROLO observations at wavelengths from 350 to $2450 \mathrm{~nm}$. Consequently, the model provides the exo-atmospheric lunar spectral irradiance with high precision for any given location and time within the model's valid geometric range of phase angles \pm 90 degrees. Berkoff et al. (2011) combined this information with nocturnal photometric measurements using a classical Cimel CE-318 sunphotometer to obtain atmospheric columnar multi-wavelength $\tau_{\mathrm{a}}$ values. They studied this magnitude for two different atmospheric conditions near full-moon, and used a sunphotometer that was limited by a non-ideal laboratory based calibration. However, their results showed relatively low differences between observed $\tau_{\mathrm{a}}$ values and those retrieved by close-in-time AERONET observations in the case of low and stable $\tau_{\mathrm{a}}$ conditions. For the high and non-stable $\tau_{\text {a }}$ period, this study showed higher uncertainties in $\tau_{\mathrm{a}}$, especially in shorter-wavelength bands, resulting from the dark noise limit of the post-photodiode electronics. Moreover, these authors proposed the improvement of the photo detector signal-to-noise ratio in order to use this type of photometers during the bright half of lunar phase and over much wider range of wavelengths and conditions. Concerning problems derived from calibration uncertainties, they can be partially fixed with a mountain-top Langley calibration or collocating stellar reference measurements.

Another problem presented in lunar photometry is the reduced observational frequency compared to sun-photometry. In case of having a sufficiently precise instrument capable of measuring under moon fraction of illumination $\geq 40 \%$ conditions, we could obtain a nocturnal useful observational percentage $<60 \%$ in a moon cycle. However, and due to the phase lag between lunar and solar cycles, only a fraction of each night will be useful in practice for moon measurements, except for full moon events, when lunar observations can cover the entire night.

In this study, we have used two prototypes of a new instrument developed by Cimel Electronique for lunar photometry, trade name CE-318U photometer, specifically designed to track the moon and to perform automatic lunar irradiance measurements. These instruments were installed at the high mountain Izaña Observatory (2400 m a.s.1.) in order to characterise their performance, to obtain absolute calibrations and to develop a reliable and trustable validation against reference instruments. We examined $\tau_{\mathrm{a}}$ and $\alpha$ retrievals under very different nocturnal atmospheric conditions, including saharan dust intrusions with high $\tau_{\mathrm{a}}$, during a relatively long period, and compared them with daytime observations.

This paper starts with a brief description of the experimental site and its facilities (Sect. 2). In Sect. 3, the CE-318U instrument is briefly described as well as the main spectral and temporal characteristics of the lunar measurements. In Sect. 4, we detail the methodology to obtain $\tau_{\mathrm{a}}$ and $\alpha$, which requires an ad-hoc calibration procedure in case of lunar observations. Three methods have been used to assess the instrument calibration: the Lunar-Langley Method, the calibration transference from a master, and the calibration using 
an integrating sphere, which are presented in Sect. 5. The main results of this study are summarised in Sect. 6, where we analyse and compare lunar $\tau_{\mathrm{a}}$ obtained by means the Lunar-Langley and our ROLO model implementation, showing some case analysis. We also compared $\tau_{\mathrm{a}}$ and $\alpha$ obtained during night period with daytime $\tau_{\mathrm{a}}$ and $\alpha$. Finally, the main conclusions of this work are presented in Sect. 7.

\section{Site information}

The high mountain Izaña Observatory, managed by the Izaña Atmospheric Research Centre (IARC), from the State Meteorological Agency of Spain (AEMET) is located in Tenerife (Canary Islands, Spain; $28^{\circ} 18^{\prime} \mathrm{N}, 16^{\circ} 29^{\prime} \mathrm{W}, 2363 \mathrm{~m}$ a.s.1.). This observatory is most of the time representative of free troposphere conditions, mainly in the night period where a downward catabatic regime is well established, providing excellent conditions for accurate measurements of trace gases. A strong temperature inversion layer normally located between 800 and $1500 \mathrm{~m}$ a.s.l., below the Izaña level, prevents the arrival of local or regional pollution from lower levels at the Observatory. This Observatory is part of the World Meteorological Organization (WMO) Global Atmospheric Watch Programme (GAW) and part of the Network for the Detection of Atmospheric Composition Change (NDACC). Furthermore, Izaña is a suitable place for sky observations due to a high atmospheric stability, high frequency of pristine days, a low and stable total column ozone and a very dry atmosphere. Several radiometric techniques, such as FTIR (Fourier Transform Infrared spectrometry), UV (i.e., Brewer spectrophotometers), DOAS (Differential Optical Absorption Spectroscopy) and Lidar have been used for a long time.

For our purposes it is worthy to highlight that Izaña Observatory is a direct-sun calibration site of AERONET (http://aeronet.gsfc.nasa.gov) and for its associated networks PHOTONS (PHOtometrie pour le Traitement Operationnel de Normalisation Satellitaire; http://loaphotons.univ-lille1. fr/photons/) and RIMA (Red Ibérica de Medida fotométrica de Aerosoles; http://www.rima.uva.es). In fact, PHOTONS, RIMA and IARC forms the present AERONET-Europe calibration infrastructure within the European project ACTRIS (Aerosols, Clouds and Trace gases Research InfraStructure Network; http://www.actris.net), and Izaña Observatory is the site where master sunphotometers of AERONET-Europe are sun-calibrated. Izaña Observatory is part of the GAW Precision Filter Radiometer (PFR) network, managed by the World Radiation Centre (Davos; Switzerland), whose mission is to obtain high accuracy long-term $\tau_{\mathrm{a}}$ and $\alpha$ series. Finally, Izaña Observatory hosts the reference triad of the WMO-GAW Regional Brewer Calibration Centre for Europe (RBCC-E) (http://www.rbcc-e.org).

\section{Instrumentation}

\subsection{The new Lunar Cimel CE-318U}

The new lunar Cimel CE-318U photometer is, in essence, a similar instrument to the classical sunphotometer Cimel CE318, extensively described in Holben et al. (1998), but with new improvements and features introduced to allow the retrieval of the reduced incoming energy from the moon. This new instrument performs nocturnal measurements with maximum gain and an approximate field of view of $1.29^{\circ}$ at eight nominal wavelengths of $1640,1020,938,937,870,675,500$ and $440 \mathrm{~nm} .380 \mathrm{~nm}$ and $340 \mathrm{~nm}$ channels were not included due to the low incoming energy received from the moon in this spectral range. A sequence of three measurements is taken every $30 \mathrm{~s}$ at each wavelength. These triplets allow us to detect and screen clouds in the same way that they are used in sun-photometry (Smirnov et al., 2000). A new moon tracker has been built in the system. It is based in a fourquadrant detector with new electronics to amplify the signal, incorporating a new software to process data while tracking. This new tracker is also able to track the sun with a special device containing an attenuation filter to reduce the high incoming energy.

CE-318U combines the features of the standard Cimel sunphotometers with a rather good signal-to-noise ratio (better than $60 \mathrm{~dB}$ ). We have estimated the instrument's precision by means of triplets stability calculation for both diurnal and nocturnal measurements, following Holben et al. (1998). This magnitude accounts for both electronic and instrumental errors. As in sun photometry, each triplet value is defined as the maximum minus minimum raw data divided by the mean value of the three consecutive measurements taken every $30 \mathrm{~s}$. Results are presented in Table 1 . Triplets values are wavelength dependent and, in case of nocturnal measurements, they are also dependent on the moon's phase. They are appreciably lower for direct-sun measurements, especially in shorter wavelength channels, where the variability in triplets is the highest. This implies that daytime measurements are more stable than nocturnal ones, although the stability in daytime and near full moon observations is quite similar.

We have used two prototypes of the new CE-318U since July 2011. The most stable was considered as the master instrument, hereinafter referred to as CE-1, and the second prototype as the secondary instrument, hereinafter referred to as CE-2.

In this study, we have included three different case studies. The first one involves a period of five consecutive nights in August (from 9 to 14) 2011, affected by different dust instrusions. The second one is a relatively low $\tau_{\mathrm{a}}$ case study during 11 and 12 October 2011, while the third one is a very low and constant $\tau_{\mathrm{a}}$ event during 8 to 9 February 2012 . 
Table 1. CE-318U triplets in \% obtained for two nights with different moon's fraction of illumination (FI) and for daytime measurements.

\begin{tabular}{cccccccc}
\hline & & \multicolumn{5}{c}{ Channels (nm) } \\
\hline & Type of measurements & 1020 & 1640 & 870 & 675 & 440 & 500 \\
\hline 13 December 2011 & Nocturnal (FI =87\%) & 0.36 & 0.18 & 0.23 & 0.26 & 0.61 & 0.52 \\
9 February 2012 & Nocturnal (FI =93\%) & 0.28 & 0.13 & 0.18 & 0.19 & 0.30 & 0.25 \\
22 December 2011 & Daytime & 0.09 & 0.11 & 0.09 & 0.13 & 0.15 & 0.22 \\
\hline
\end{tabular}

\subsection{The integrating sphere for radiances calibration}

A calibration system developed for the instruments performing sky radiance measurements within the AERONETPHOTONS-RIMA networks has been implemented at the Izaña Observatory. In such systems, the light source comes from an integrating sphere providing a homogeneous visual field. The recalibration of the sphere is accomplished three times a year by comparison to the travel NASA master Cimel sunphotometer (Guirado et al., 2012). Following Walker et al. (1991), the sphere's accuracy is assumed $\leq 5 \%$.

\subsection{ROLO model}

In this paper, we have used the model presented in Kieffer and Stone (2005) to calculate the lunar irradiance (ROLO model) using our own astronomical calculations. ROLO Project was established to characterise the brightness of the moon with the aim of addressing the critical calibration problems of the Earth remote-sensing imaging sensors (Kieffer and Stone, 2005). This programme was developed at the USGS Flagstaff Science Centre in Arizona as a NASAfunded project. The basis of this programme is the automated ground-based observations over multiple years to capture the cyclic brightness variation of the moon. The observatory was in operation for more than $8 \mathrm{yr}$, observing every clear night at lunar phases within $\pm 90^{\circ}$. Over 85000 lunar images were acquired in 32 wavelengths from 350 to $2450 \mathrm{~nm}$. These images form the basis data for the model, as spatially integrated lunar irradiance measurements. The ROLO model uses an empirically derived analytic equation to predict the lunar disk-equivalent reflectance $\left(A_{j}\right)$ in the spectral band $j$ using only geometric variables (Kieffer and Stone, 2005),

$$
\begin{gathered}
\ln \left(A_{j}\right)=\sum_{n=1}^{3} a_{i, j} g^{i}+\sum_{n=1}^{3} b_{n, j} \varphi^{2 n-1}+c_{1} \cdot \theta+c_{2} \cdot \phi \\
\quad+c_{3} \cdot \varphi \cdot \theta+c_{4} \cdot \varphi \cdot \phi+d_{1, j} \\
\quad e^{\frac{-g}{p_{1}}}+d_{2, j} \cdot e^{\frac{-g}{p_{2}}}+d_{3, j} \cdot \cos \left(\frac{g-p_{3}}{p_{4}}\right)
\end{gathered}
$$

where $g$ is the absolute phase angle, $\theta$ and $\phi$ are the selenographic latitude and longitude of the observer, respectively, and $\varphi$ is the selenographic longitude of the sun.

Kieffer and Stone (2005) found band-average absolute residuals about $1 \%$ by comparison between ROLO empirical irradiances and hundreds of ROLO observations. Con- sequently, ROLO provides the exo-atmospheric lunar irradiance with a relatively high precision over the full range of the geometric variables and wavelengths at a specific location and time. Since our modelled irradiances were computed using a different astronomical ephemeris calculator and taking into account that ROLO provides $I_{0}$ modelled values for 32 specific spectral responses, a lower level of accuracy in our ROLO-implemented model is expected. In this study, we have used the Alcyone ephemeris 4.3, based on the Moshier's ephemeris and the celestial mechanics equations from Meeus (1991), both adjusted to the Jet Propulsion Laboratory's DE404 results. It has an expected precision within $0.5^{\prime \prime}$ in moon's longitude, $0.33^{\prime \prime}$ in latitude and $0.36 \mathrm{~km}$ in distance.

\subsection{Ancillary information for data validation}

$\tau_{\mathrm{a}}$ and $\alpha$ version 2 level 1.5 data obtained with the Izaña AERONET master \#244 (http://aeronet.gsfc.nasa.gov), near sunset and near sunrise, are used to compare with $\tau_{\mathrm{a}}$ and $\alpha$ determined with CE-1 and CE-2 at moonrise and moonset, respectively. Following Eck et al. (1999), the expected total uncertainty in $\tau_{\mathrm{a}}$ for field AERONET Cimel instruments is 0.010-0.021, and 0.002-0.009 for master instruments.

A 4-wavelength GAW PFR developed by the World Optical Depth Research and Calibration Centre (WORCC) of the PMOD World Radiation Centre (http://www.pmodwrc. ch/worcc/index.html) is in operation at Izaña since July 2001. PFR near sunset and near sunrise $\tau_{\mathrm{a}}$ at 412.1, 501.0, and $863.1 \mathrm{~nm}$, as well as $\alpha$, were used as an additional reference to validate the CE1 and CE- 2 data. Low $\tau_{\mathrm{a}}$ differences between PFR and AERONET Cimel, in case of instantaneous measurements, have been reported by Nyeki et al. (2012) (0.0024 measured at Davos). Mean bias differences of 0.002 and 0.003 between PFR and AERONET Cimel were recorded at Izaña during 2011 (Christoph Wehrli, personal communication, 2012).

A Micropulse Lidar (MPL), MPL-3 (SES Inc., USA) system (Spinhirne et al., 1995) has been running at Santa Cruz de Tenerife station $\left(28.5^{\circ} \mathrm{N}, 16.2^{\circ} \mathrm{W} ; 52 \mathrm{~m}\right.$ a.s.l.) since January 2005. This program has been implemented for monitoring and characterization of Saharan Air Layer (SAL) North Atlantic outflow, and it is currently in operation within NASA/MPLNET (hhtp://mplnet.gsfc.nasa.gov), and is comanaged by National Institute for Aerospace Technology 
(INTA; Spain) and the Izaña Atmospheric Research Centre (IARC; AEMET). MPL is a robust system with highpulse frequency $(2500 \mathrm{~Hz})$ and low-energy $(7-10 \mu \mathrm{J}$, maximal) "eye-safe" Nd:YLF laser at $523 \mathrm{~nm}$ operational in fulltime continuous mode ( $24 \mathrm{~h}$ a day/365 days a year). Lidar backscattered signal is registered in 1-min integrated time and with a vertical resolution of $75 \mathrm{~m}$. Details of the MPL and the on-site maintenance and calibration techniques are described by Campbell et al. (2002). It is used to track the SAL dust layering structure evolution from day to day, and be compared qualitatively with $\tau_{\mathrm{a}}$ evolution obtained with AERONET and lunar photometers. In this study, we have processed lidar data and obtained backscatter cross sections.

FLEXible backward TRAjectories (FLEXTRA) plots from the EMPA facility for Global GAW stations have been used to confirm the pathways of air masses arriving to Izaña at several levels (Stohl et al., 1995; Stohl and Seibert, 1998). The calculations are based on the FLEXTRA model and driven by ECMWF wind fields with a global resolution of $1^{\circ} \times 1^{\circ}$. FLEXTRA trajectory images are available at http: //lagrange.empa.ch/.

\section{Methodology}

\subsection{Aerosol Optical Depth determination - The Lunar-Langley Method}

Attenuation of moon's irradiance in an atmospheric window, as occurs during daytime, can be described by the BeerLambert-Bouguer Law:

$V_{\lambda}=V_{0, \lambda} \cdot \exp \left(-m(\theta) \cdot \tau_{\lambda}\right)$

where $V_{\lambda}$ is the output voltage, $V_{0, \lambda}$ represents the extraterrestrial voltage, which includes all temporal variations (lunar phase as well as earth-moon and moon-sun distances), $m$ is the relative optical mass, function of the moon's zenith angle $\theta$, and $\tau_{\lambda}$ is the spectral optical depth. For the air mass and the spectral optical depth calculation we have followed the specifications corresponding to AERONET version 2. Moon's zenith angle $(\theta)$ has been obtained using the ephemeris Alcyone 4.3. Taking logarithms on both sides of Eq. (2) we have,

$\ln \left(V_{\lambda}\right)=\ln \left(V_{0, \lambda}\right)-m(\theta) \cdot \tau_{\lambda}$

To account for the change in moon's illumination during the course of the night as well as the distance effect on lunar irradiance, we have introduced in Eq. (2) these the two contributions on the $V_{0}$ term. Thus,

$V_{0, j}=I_{0, j} \cdot \kappa_{j}$

where $I_{0, j}$ is the extraterrestrial irradiance in a certain channel with a central wavelength at $j$, and $\kappa_{j}$ is a constant that depends on the instrument features (calibration coefficients, $C_{j}$, and the instrument solid angle field-of-view, $\Omega$ ).
$I_{0, j}$ is calculated using the ROLO lunar disk-equivalent reflectances $\left(A_{j}\right)$ in Eq. (1). It takes into account lunar phase as well as sun-moon distance. In this work, the sun-moon distance as well as the selenographic latitude and longitude of the observer and the sun are computed using the astronomical calculator previously described. Lunar reflectances are converted to modelled irradiances using the following expression,

$I_{j}=\frac{A_{j} \cdot \Omega_{\mathrm{M}} \cdot E_{j}}{\pi}$

In this equation $\Omega_{\mathrm{M}}$ is the moon's solid angle, dependent on the moon-earth distance and $E_{j}$ is the solar spectral irradiance for the band $j$. Following Kieffer and Stone (2005), to obtain the last term the irradiance model of Wehrli (1986) has been assumed,

$E_{j}=\frac{\int_{\lambda_{1}}^{\lambda_{2}} E_{\mathrm{s}}(\lambda) \cdot R(\lambda) d \lambda}{\int_{\lambda_{1}}^{\lambda_{2}} R(\lambda) d \lambda}$

where $E_{\mathrm{S}}(\lambda)$ is the sun's spectral irradiance at $1 \mathrm{AU}$ and $R(\lambda)$ is the filter response function for each spectral band of CE-318U. Regarding $\Omega_{\mathrm{M}}$, it is obtained using the topocentric apparent diameter of the moon $\left(d_{\text {app }}\right)$, function of earth-moon distance,

$\Omega_{\mathrm{M}}=\pi \cdot\left(\sin \frac{d_{\text {app }}}{2}\right)^{2}$

With all these inputs on the Eqs. (1) and (5) moon's irradiance was calculated coincidentally with each CE$318 \mathrm{U}$ measurement.

The calibration methodology for nocturnal photometry proposed here for nighttime measurements is called LunarLangley Method. It uses Eqs. (3) and (4) and a least squares fitting to obtain the instrument's calibration constant $\left(\kappa_{j}\right)$ as the intercept of the fitting line. In this case $\kappa_{j}$ constants strictly accounts for the instrument's photometric responsivity and any residual systematic offset difference between ROLO predicted $I_{0, j}$ and the actual exoatmospheric irradiance. Thus, it must be ideally computed as an average of some Lunar-Langley's obtained in a mountain-top station under suitable atmospheric conditions.

As in daytime period, a good Lunar-Langley calibration requires clean, cloud-free and stable atmospheric conditions. For this reason it is commonly applied in sun-photometry over a range of air masses between 2 and 5 during sunrise or sunset. In this study, we have used the Lunar-Langley methodology to obtain the calibration constants $\kappa_{j}$ 's under stable and clear atmospheric measurements, over a range of air masses between 2 and 5 (during the moonrise or the moonset).

Once $\kappa_{j}$ 's are known by means of the Lunar-Langley Method, it is possible to determine instantaneous $\tau_{\mathrm{a}}$ from an individual measurement:

$\tau_{\mathrm{a}, j}=\frac{\ln \left(\kappa_{j}\right)-\ln \left(\frac{V_{j}}{I_{0, j}}\right)-m_{\mathrm{atm}}(\theta) \cdot \tau_{\mathrm{atm}, j}}{m_{\mathrm{a}}(\theta)}$ 
Table 2. CE-1 solid angle (in steradians) determined with daytime measurements.

\begin{tabular}{ccccccc}
\hline Channel $(\mathrm{nm})$ & 1020 & 1640 & 870 & 675 & 500 & 440 \\
\hline$\Omega_{j}$ & $3.92 \times 10^{-4}$ & $3.95 \times 10^{-4}$ & $3.93 \times 10^{-4}$ & $3.88 \times 10^{-4}$ & $3.82 \times 10^{-4}$ & $3.78 \times 10^{-4}$ \\
\hline
\end{tabular}

The subscript "atm" accounts for air mass and optical depth of each atmospheric attenuator with the exception of aerosols.

\subsection{Angström's exponent ( $\alpha)$ determination}

The Angström's exponent $(\alpha)$ is a measure of the wavelength dependence of the $\tau_{\mathrm{a}}$ (Angström, 1929). $\alpha$ is a qualitative indicator of aerosol particle size (Kaufman et al., 1994), as it is inversely related to the particle size (Kim et al., 2011). Thus, the combined $\alpha-\tau_{\mathrm{a}}$ information is useful to discriminate different atmospheric aerosol types.

To obtain this parameter we have retrieved $\tau_{\mathrm{a}}$ within the spectral range between $870 \mathrm{~nm}$ and $440 \mathrm{~nm}$. Taking the slope of the linear fit to the logarithm of $\lambda_{j}$ vs. logarithm of $\tau_{\mathrm{a}}\left(\lambda_{j}\right)$ ( $j=870,675,500$ and $440 \mathrm{~nm}$ channels), we can obtain $\alpha$ using the following equation:

$\ln \left(\tau_{\mathrm{a}}\left(\lambda_{j}\right)\right)=\ln (\beta)-\alpha \cdot \ln \left(\lambda_{j}\right)$

Another important parameter is the spectral variation of $\alpha$ $(\delta \alpha)$. It reports additional information about the aerosol size distribution, and it is expressed as,

$\delta \alpha=\alpha(440,675)-\alpha(675,870)$

Positive values of $\delta \alpha$ indicate the coexistence of two separate particle modes. Eck et al. (1999), with a case analysis in the Gobi desert, and Basart et al. (2009) with a climatology from 32 AERONET stations in Northern Africa and Middle East, demonstrated that relatively small negative values of $\delta \alpha$ indicate the presence of pure desert mineral dust.

\subsection{Instrument solid angle field-of-view determination}

The solid angle field-of-view (solid angle FOV or $\Omega$ ) of a photometer is normally provided by the manufacturer. However, in this work we have calculated it following the methodology proposed by Li et al. (2008). It computes $\Omega$ from daytime measurements using the aureole calibration coefficients $\left(C_{\mathrm{a}}\right)$ and instrument user and internal gains, instead of computing them by means of the classical laboratory method. The $C_{\mathrm{a}}$ coefficients are obtained by means of a calibration using an integrating sphere. These authors obtained from error propagation expected uncertainties between $3 \%$ and $5 \%$. They propose the following definition for $\Omega$ :

$\Omega=\Omega_{\mathrm{g}} \cdot \frac{\mathrm{LG}}{\mathrm{HG}_{\mathrm{a}}}=\left(\frac{E_{0}}{V_{0, \mathrm{~s}} \cdot C_{\mathrm{a}}}\right) \cdot \frac{\mathrm{LG}}{\mathrm{HG}_{\mathrm{a}}}$

where $\Omega_{\mathrm{g}}$ is the solid angle gain corrected, $\mathrm{LG}$ and $\mathrm{HG}_{\mathrm{a}}$ are the direct and aureole instrument internal electronic gains, respectively, $E_{0}$ is the extraterrestrial solar irradiance, $V_{0, \mathrm{~s}}$ is the solar extraterrestrial constant and $C_{\mathrm{a}}$ are the aureole radiance calibration coefficients, obtained using the integratingsphere calibration technique.

Results of $\Omega_{j}$ are shown in Table 2, showing a spectral dependence on this magnitude. This slight wavelength dependence was also found by $\mathrm{Li}$ et al. (2008), although they propose to average the spectral $\Omega_{j}$ over all wavelengths to derive a constant value.

\section{Calibration strategy}

As for sunphotometers, lunar-photometers need a calibration procedure in order to obtain $\tau_{\mathrm{a}}$ and $\alpha$, and to assess their reliability and intercomparability. Sunphotometer's calibration usually needs the estimation of the voltage measured by the instrument in absence of atmosphere by extrapolation of the voltage curve in Eq. (2) to zero air mass conditions. This calibration procedure is known as Langley-plot method. It uses the sun or, as in this case, the moon as a reference light source. However, this methodology must be re-formulated to account for the moon's irradiance variation inherent to the lunar cycle.

In this paper, we present the calibration strategy for the lunar CE-318U instrument, which can be approached by three different methods, depending on available calibration facilities.

\subsection{Method\#1: Lunar-Langley calibration}

The first method implies the determination of the calibration constants $\kappa_{j}$ by means of the Lunar-Langley Method expressed by using the Eqs. (3) and (4). This Method requires the knowledge of the moon's extraterrestrial irradiance at any time of measurement. Once raw data and $I_{0}$ 's are ratioed, the calibration constants $\kappa_{j}$ can be determined as the intercept of the least squares fitting in Eq. (3).

We have performed this calibration technique for both CE-1 and CE-2 using the lunar data obtained on 8-9 February 2012. This night was selected due to the relatively low and constant $\tau_{\mathrm{a}}$ conditions, especially during moonset, where $\tau_{\mathrm{a}}$ at $440 \mathrm{~nm}$ remained stable and near 0.02 . For CE-1, this calibration was applied in other two time periods to check the stability of the calibration. In Fig. 1 the Lunar-Langley analysis performed for CE-1 is shown. High correlation coefficients of the linear regression analysis $(R \geq 0.99)$ were found for all channels except for $1020 \mathrm{~nm}$ channel $(R=0.79)$, showing the reliability of the calibration procedure. The 


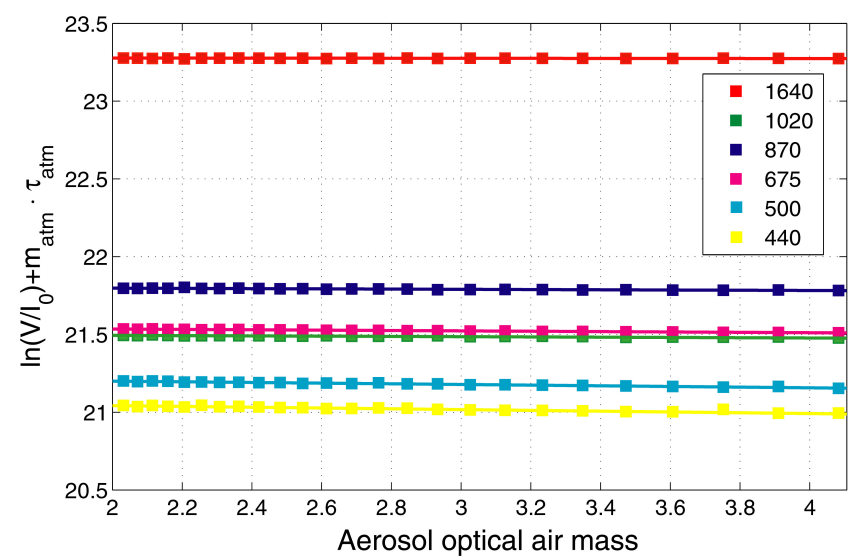

Fig. 1. Lunar Langley-plot analysis performed on the moonset of 9 February for CE-1.

considerable deviations in $1020 \mathrm{~nm}$ channel can be attribute to the temperature dependence effect on this spectral range.

\subsection{Method\#2: calibration transference from a master}

The previous calibration method is very accurate, if suitable atmospheric conditions exist. For this reason, it can only be applied in mountain-top sites where very low and stable $\tau_{\mathrm{a}}$ exists, as well as low humidity nighttime conditions can be attained. Only a few sites can meet these requirements, so an alternative calibration method is needed. The second proposed method is that followed by classical sunphotometers by means of intercomparisons. It is based on the calibration transference from a master instrument (Holben et al., 1998; Toledano et al., 2011), in turn calibrated at a high mountain site. This transference technique is possible taking into account the average ratio in digital counts between coincident measurements from two lunar photometers. Being $\left(\overline{\mathrm{DC}_{\mathrm{M}}}\right)$ and $\left(\overline{\mathrm{DC}_{\mathrm{i}}}\right)$ the average coincident raw data for the master and the instrument $i$ to be calibrated, respectively, we can obtain the calibration constant $V_{0, i}$ using the known value $V_{0, \mathrm{M}} \mathrm{ob}-$ tained from a master, with the following expression:

$V_{0, i}=V_{0, \mathrm{M}} \cdot \frac{\overline{\overline{\mathrm{DC}_{i}}}}{\overline{\mathrm{DC}_{\mathrm{M}}}}$

\subsection{Method\#3: calibration using an integrating sphere}

A third method to calibrate a lunar photometer is based on the use of an integrating sphere to determine the sky calibration coefficients $C_{j}$, as Berkoff et al. (2011) followed, and the laboratory procedure developed by Li et al. (2008) to calculate $\Omega_{j}$. The instrument calibration constants $\kappa_{j}$ can be determined as follows,

$\kappa_{j}=\frac{1}{C_{j} \cdot \Omega_{j}}$

From Eqs. (4) and (13) we can determine experimentally the calibration constants for our instrument $\left(\kappa_{j}\right.$ 's) deriving $C_{j}$ and $\Omega_{j}$. Then, it could be possible to convert at any time ROLO exo-atmospheric irradiances into the instrument $V_{0, j}$ parameter. $V_{0, j}$ inferred using this method has an accuracy strongly limited by the uncertainties involved in the determination of $C_{j}$ and $\Omega_{j}$, as well as those involved in the ROLO model.

In this study, we have used an integrating sphere calibration system implemented for PHOTONS-RIMA calibration at IARC. The main features of the integrating-sphere were described in Sect. 3.2.

\section{Results}

\subsection{Method\#1}

The calibration constants $\kappa_{j}$ 's were calculated using this Lunar-Langley calibration for the two CE-318U prototypes using nocturnal measurements on the moonset of 9 February 2012, for CE-1, and the moonrise for CE-2, as no data was available for CE-2 during the moonset. This was the most pristine and stable event to perform an accurate Langley calibration. The coefficients of the two instruments are shown in Table 3.

Using calibration constants from this table, nocturnal $\tau_{\mathrm{a}}$ for CE-1 have been calculated for 9-10, 10-11, 11-12, 1213 and 13-14 August 2011 and for two episodes more on 1112 October 2011, and 8-9 February 2012, with low and stable aerosol conditions. The first five nights period in August involved a moon' s illumination change from $84 \%$ to $100 \%$. During October event, moon's illumination was $\sim 100 \%$ (full moon), meanwhile during 8-9 February 2012, the illumination was within the $99 \%-98 \%$ range. In Figs. 2, 3 and 4 the daytime and nocturnal $\tau_{\mathrm{a}}$ evolution is presented for a sequence of six days and five nights of measurements in August and the nights in October and February. Lidar backscatter vertical cross-section is shown in addition to the $\tau_{\mathrm{a}}$ course for each episode in order to have independent qualitative information about the vertical structure and variability of the aerosols. For a quantitative analysis of daytime and nocturnal $\tau_{\mathrm{a}}$ differences, it is necessary to establish a criterion of "quasi-simultaneity". In this study, we have compared nocturnal and daytime data corresponding to the consecutive 1-h time period during sunset-moonrise (SS-MR) and moonsetsunrise (MS-SR): the first hour of the moonrise against the last hour of previous daytime data during sunset, as well as the last hour of the moonset against the first hour of subsequent daytime $\tau_{\mathrm{a}}$ during sunrise. These results are shown in Table 4.

\subsubsection{High $\tau_{\mathrm{a}}$ conditions: saharan dust events}

We used the information from FLEXTRA backward trajectories in order to infer dust source regions in the high $\tau_{\mathrm{a}}$ events assigned to August 2011. They show air mass pathways over the Sahara and the Sahel in several height levels 
Table 3. $\kappa_{j}$ calibration constants extracted for each channel (in $\mathrm{nm}$ ) for CE-1 and $\kappa^{\prime}$ constants for CE-2, both obtained on 9 February 2012 $\left(\mathrm{W}^{-1} \mathrm{~m}^{2} \mathrm{~nm} \mathrm{DC}\right)$.

\begin{tabular}{|c|c|c|c|c|c|c|c|}
\hline \multicolumn{2}{|c|}{ Channel (nm) } & 1020 & 1640 & 870 & 675 & 500 & 440 \\
\hline $\mathrm{CE}-1 \kappa_{j}$ & mean & $2.15 \times 10^{9}$ & $1.28 \times 10^{10}$ & $3.02 \times 10^{9}$ & $2.29 \times 10^{9}$ & $1.74 \times 10^{9}$ & $1.41 \times 10^{9}$ \\
\hline CE- $2 \kappa_{j}$, & mean & $2.01 \times 10^{9}$ & $1.15 \times 10^{10}$ & $2.74 \times 10^{9}$ & $2.10 \times 10^{9}$ & $1.64 \times 10^{9}$ & $1.33 \times 10^{9}$ \\
\hline
\end{tabular}

Table 4. $\tau_{\mathrm{a}}$ averaged differences between daytime AERONET and CE-1 data during sunset-moonrise (SS-MR, as the last 1-h of daytime AERONET data versus the first 1-h of nocturnal CE-1 data) and moonset-sunrise (MS-SR, as the first 1-h of daytime AERONET data versus the last 1-h of nocturnal CE-1 data).

\begin{tabular}{rcrrrrrr}
\hline & Channel (nm) & 1020 & 1640 & 870 & 675 & 500 & 440 \\
\hline \multirow{2}{*}{ 9-10 August 2011 } & SS-MR & 0.001 & 0.005 & -0.003 & 0.011 & -0.002 & -0.006 \\
& MS-SR & - & - & - & - & - & - \\
\cline { 2 - 7 } 10-11 August 2011 & SS-MR & -0.010 & -0.001 & -0.007 & -0.008 & -0.009 & 0.015 \\
& MS-SR & 0.015 & 0.008 & 0.005 & 0.006 & 0.004 & -0.003 \\
\cline { 2 - 7 } 11-12 August 2011 & SS-MR & -0.017 & -0.007 & -0.015 & -0.015 & -0.016 & -0.017 \\
& MS-SR & -0.012 & -0.010 & -0.013 & -0.015 & -0.018 & -0.023 \\
\cline { 2 - 7 } 12-13 August 2011 & SS-MR & -0.016 & -0.009 & -0.021 & -0.021 & -0.022 & -0.019 \\
& MS-SR & -0.019 & -0.019 & -0.023 & -0.025 & -0.028 & -0.029 \\
\cline { 2 - 7 } 13-14 August 2011 & SS-MR & -0.014 & -0.009 & -0.013 & -0.013 & -0.014 & -0.013 \\
& MS-SR & -0.024 & -0.035 & -0.032 & -0.032 & -0.031 & -0.032 \\
\cline { 2 - 7 } 11-12 October 2011 & SS-MR & 0.002 & 0.007 & 0.008 & 0.006 & 0.007 & 0.005 \\
& MS-SR & -0.007 & -0.005 & -0.003 & -0.004 & -0.002 & -0.003 \\
\cline { 2 - 7 } 8-9 February 2012 & SS-MR & -0.006 & -0.009 & -0.011 & -0.014 & -0.016 & -0.015 \\
& MS-SR & 0.001 & 0.001 & 0.001 & -0.002 & -0.002 & -0.003 \\
\hline
\end{tabular}

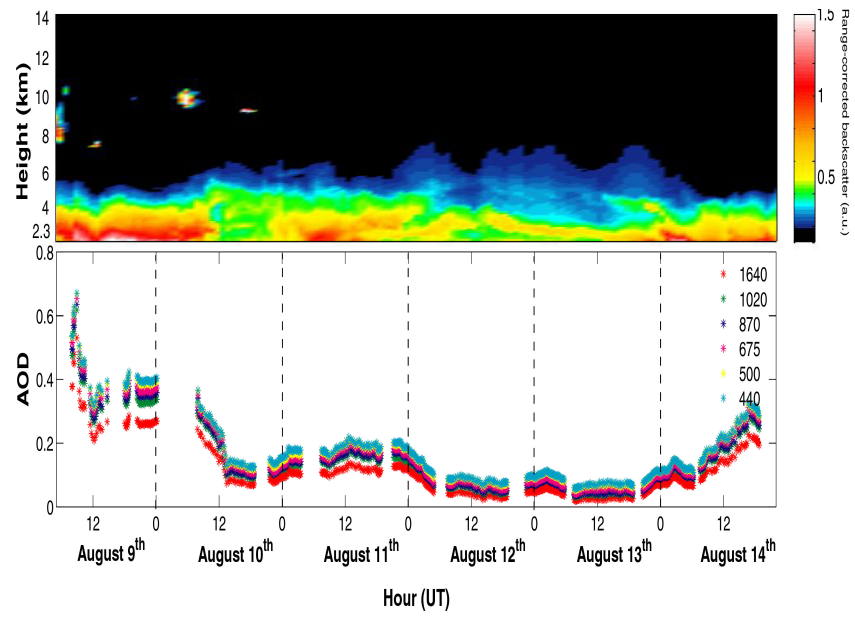

Fig. 2. $\tau_{\text {a }}$ evolution during six days and five nights on August 2011, using AERONET data for daytime and lunar CE-1 data for nocturnal period. MPL corrected backscatter cross-sections obtained at Santa Cruz station from the Izaña Observatory level in upper panel.

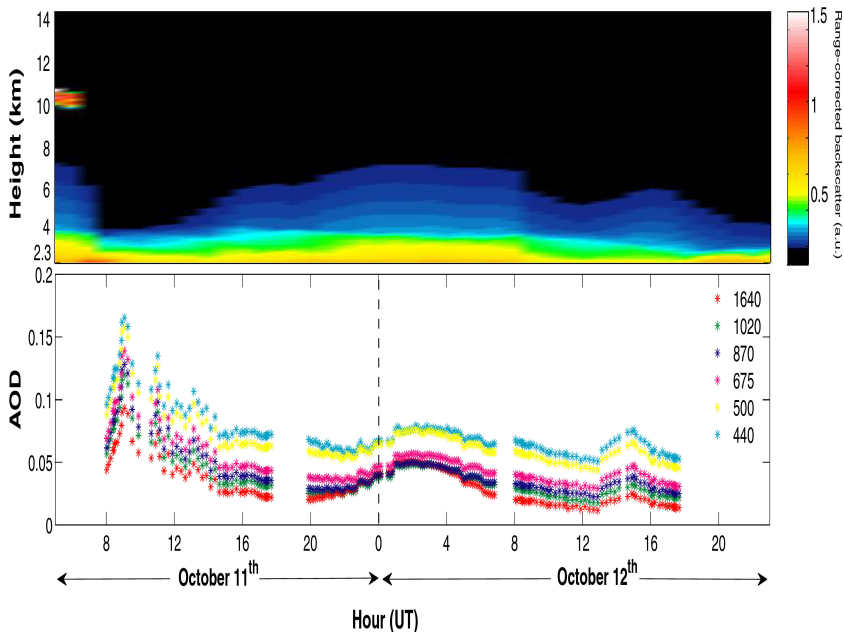

Fig. 3. CE- $1 \tau_{\mathrm{a}}$ on 11 and 12 October 2011, with MPL corrected backscatter cross-sections for the same period from the Izaña Observatory level (upper panel). 
above Izaña Observatory up to $5500 \mathrm{~m}$ a.s.l. from 9 to $14 \mathrm{Au}-$ gust (not shown here for the sake of brevity). These saharan dust intrusions during 9 and 10 August are clearly seen in Fig. 2. The first event is detected by the MPL with a maximum backscatter signal between 2.3 and $4 \mathrm{~km}$ height from 9 August to 10 August midday. After this time the signal decreases sharply, with minimum values at night. During this period some high clouds are detected by MPL at a height above $8 \mathrm{~km}$ and, thus, $\tau_{\mathrm{a}}$ can be affected. Differences during moonrise and sunset on 9 August are below 0.01 (Table 4), whithin the $\tau_{\mathrm{a}}$ accuracy limit established in AERONET (Holben et al., 1998). Nocturnal data was not available to perform moonset and sunrise comparison on 10 August. In the same day, these differences reached 0.02 in $440 \mathrm{~nm}$ during the moonrise, meanwhile they were reduced to values below 0.01 in the next moonset-sunrise period, when another intrusion started on 11 August. From 05:00 to 23:00 UTC, approximately, and after this period the backscatter signal decreased slowly. This change in aerosol concentration was well captured by CE-1, with a $\tau_{\text {a }}$ decreasing from values up to 0.20 in $440 \mathrm{~nm}$ during the early night to lower than 0.10 in $440 \mathrm{~nm}$, and near constant values during the latest part of this night. From Table 4 we can see that sunset-moonrise and moonset-sunrise $\tau_{\mathrm{a}}$ differences are similar, below 0.02 for all channels. We had a third intrusion in this period, on 13 August. In this case, the aerosol layer extended up to $5 \mathrm{~km}$ altitude, starting at about 22:00 UTC. The dust layer is perfectly captured by the lidar profile and compares quite well to the aerosol optical depth curves obtained with CE-1. Nocturnal $\tau_{\mathrm{a}}$ differences during the 12-13 August reached 0.02 for sunset-moonrise and 0.03 for moonset-sunrise in shorter wavelength channels. During the moonset and sunrise of 14 August differences grew to 0.04, due to the sharp $\tau_{\mathrm{a}}$ increase. Meanwhile, in the sunset-moonrise of 13 August, just when this intrusion starts, $\tau_{\mathrm{a}}$ differences are about 0.01 . Although most of the differences found were higher than the AERONET accuracy limit for $\tau_{\mathrm{a}}$, they are explained by the high aerosol variability.

Additional information can be extracted from Table 4 . Similar $\tau_{\mathrm{a}}$ differences during two stable nights with different moon's illumination, 9-10 August (with a mean lunar illumination of $84.7 \%$ ) and 11-12 October (near full moon, $99.8 \%$ ), were found and, thus, we can assume that $\tau_{\mathrm{a}}$ accuracy is not affected by a change in $\sim 15 \%$ in fraction of illumination.

\subsubsection{Low $\tau_{\mathrm{a}}$ conditions}

In order to test the performance of this new instrument over low and stable aerosol concentrations, we have included two additional events. The first clean event showed a $\tau_{\mathrm{a}}$ relatively constant (around 0.07 at $440 \mathrm{~nm}$ ) test case during two consecutive days (11 and 12 October 2011), shown in Fig. 3. This figure demonstrates a good agreement between vertical aerosol backscatter evolution and $\tau_{\mathrm{a}}$, as well as be-

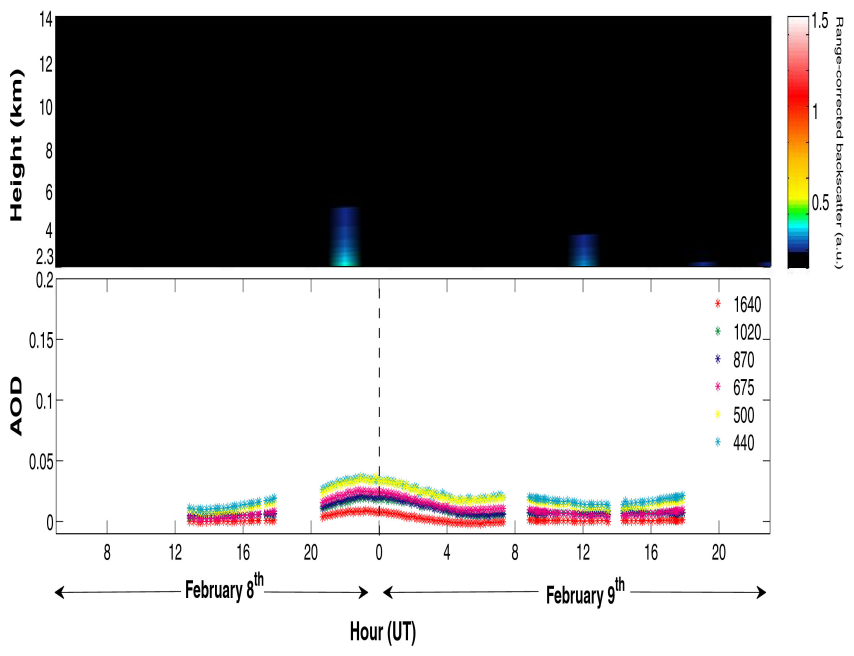

Fig. 4. CE-1 $\tau_{\mathrm{a}}$ on 8 and 9 February 2012, with MPL corrected backscatter cross-sections from the Izaña Observatory level.

tween AERONET and CE- $1 \tau_{\mathrm{a}}$ values. In Table $4, \tau_{\mathrm{a}}$ differences are $\leq 0.01$ during both sunset-moonrise and moonsetsunrise. Although the increment in aerosol concentration during nighttime is well captured by CE-1, it can be seen from Fig. 3 a probable calibration problem affecting the $1640 \mathrm{~nm}$ and $1020 \mathrm{~nm}$ channels between moonrise and moonset. We attribute discrepancies in $1020 \mathrm{~nm}$ to temperature correction. However, discrepancies in $1640 \mathrm{~nm}$ do not seem to be related to a general problem in longer wavelengths, but in particular uncertainties associated to astronomical parameters determination for a particular night.

The second clean event was on 8-9 February 2012 (Fig. 4). This is a very clear night ( $\tau_{\mathrm{a}}$ at 440 between 0.02 and 0.04 ) with a relatively stable aerosol concentration during the entire night, especially over the moonset period. On 9 February a Lunar-Langley was performed. In this case, as expected, moonset data matches pretty well AERONET sunrise data. Differences are slightly greater during moonrise but within the AERONET $\tau_{\mathrm{a}}$ accuracy limit.

$\tau_{\mathrm{a}}$ validation has been completed with daytime $\tau_{\mathrm{a}}$ from PFR for 11 and 12 October 2011, and 8 and 9 February 2012. We should note that PFR has only three channels centred at $863.1,501$ and $412.1 \mathrm{~nm}$. Therefore, the comparison study can only be computed for the CE-1 near coincident channels. Due to the different central wavelength between the two instruments near $440 \mathrm{~nm}$, we have derived the PFR $\tau_{\mathrm{a}}$ at $440 \mathrm{~nm}$ from the measured value at $412.1 \mathrm{~nm}$ using the Angström expression for two wavelengths. AERONET versus PFR, as well as AERONET versus CE- $1 \tau_{\mathrm{a}}$ differences are presented in Table 5. $\tau_{\mathrm{a}}$ differences in quasi-simultaneous AERONET and PFR $\tau_{\mathrm{a}}$ measurements are $\leq 0.013$ for all channels in October, and below 0.006 in February, similar to the differences found between PFR and CE-1 measurements, with values up to 0.012 . 
Table 5. $\tau_{\mathrm{a}}$ averaged differences on 11 to 12 October 2011, and 8 to 9 February 2012, between daytime PFR and nocturnal CE-1 data during sunset-moonrise (SS-MR, the last 1-h of daytime PFR data versus the first 1-h of nocturnal CE-1 data) and moonset-sunrise (MS-SR, as the first 1-h of daytime PFR data versus the last 1-h of nocturnal CE-1 data). $\tau_{\mathrm{a}}$ differences between PFR and AERONET during moonrise and moonset have been included.

\begin{tabular}{llrrr}
\hline & PFR Channel (nm) & 412.1 & 501 & 863.1 \\
\hline \multirow{4}{*}{ PFR/CE-1 } & Oct. SS-MR & 0.011 & 0.010 & 0.012 \\
& October MS-SR & 0.011 & 0.010 & 0.009 \\
& February SS-MR & -0.008 & -0.009 & -0.008 \\
& February MS-SR & 0.004 & 0.004 & 0.001 \\
\hline \multirow{4}{*}{ PFR/AERONET } & Oct. SS-MR & -0.005 & -0.006 & -0.004 \\
& October MS-SR & -0.012 & -0.013 & -0.012 \\
& February SS-MR & -0.004 & -0.004 & -0.001 \\
& February MS-SR & -0.005 & -0.006 & 0.001 \\
\hline
\end{tabular}

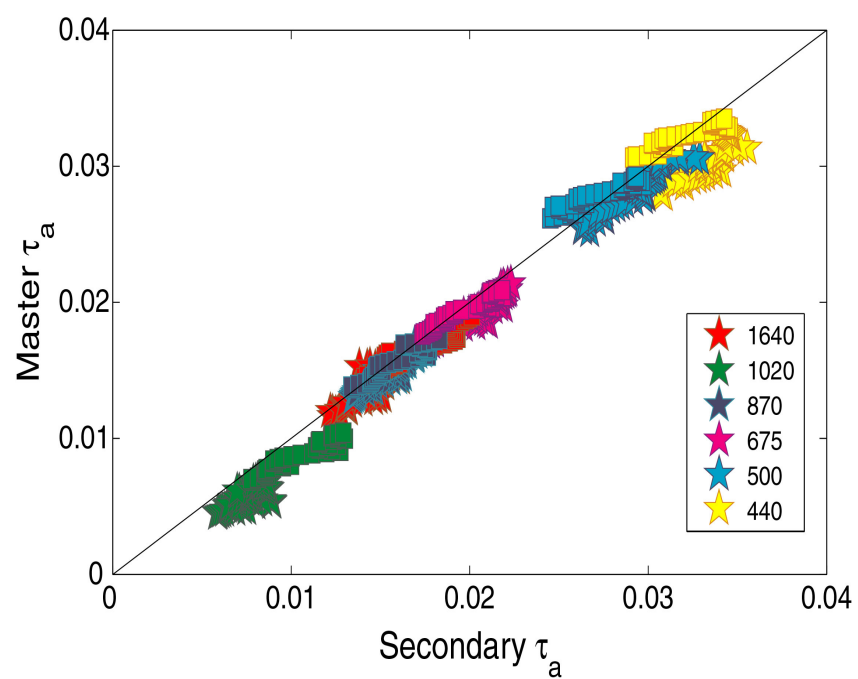

Fig. 5. $\tau_{\mathrm{a}}$ scatter-plot obtained for CE-1 (master) and CE-2 (secondary) using calibration Method\#2 for 9 February (stars) and 10 February (squares), 2012.

These results confirm the optimum performance of the CE-1 under low $\tau_{\mathrm{a}}$ conditions.

\subsection{Method\#2}

$\tau_{\mathrm{a}}$ results using Method\#2 have been evaluated for 9 and 10 February 2012. This method is based on Eq. (12) for coincident measurements with a master (CE-1) and a secondary instrument (CE-2). In our case CE-2 was calibrated using the average ratio of raw data of the two instruments during a stable and clear night period. In this sense, 9 February 2012, was the best option, with a mean background $\tau_{\mathrm{a}}(440 \mathrm{~nm}) \sim 0.02$.

The $\tau_{\mathrm{a}}$ scatter-plot obtained using CE- 1 and CE-2 is shown in Fig. 5. $\tau_{\mathrm{a}}$ comparison for 9 February and the day after the calibration (10 February) shows a good concordance between the values obtained from the master and the secondary instrument, with averaged differences below 0.003. Maxi- mum absolute differences up to 0.004 are found in $1020 \mathrm{~nm}$ and $440 \mathrm{~nm}$ channels.

\subsection{Method\#3}

The third method for a lunar photometer calibration involves the determination of the sky calibration coefficients $\left(C_{j}\right)$ using the integrating sphere procedure described in Sect. 3.2. The coefficients obtained for CE-1 using this Method are presented in Table 6. For comparison with Method\#1, we have derived the CE-1 sky calibration coefficients $\left(C_{j}^{\prime \prime}\right)$ from the $\kappa_{j}$ constants in Table 3 considering the solid-angle $\Omega_{j}$ in Table 2. These $C_{j}^{\prime \prime}$ are also presented in Table 6. Comparing these coefficients we note that those centred at 500 and $440 \mathrm{~nm}$ present higher relative differences, with values up to $25 \%$. Differences in the rest of channels are below $10 \%$. Higher discrepancies in shorter wavelengths channels might be due to uncertainties in the integrating sphere calibration technique because in these channels the sphere's radiant flux is notably reduced.

The averaged differences $\left(\overline{d_{1}}\right)$ between $\tau_{\mathrm{a}}$ obtained with the calibration coefficients calculated with this method $\left(C_{j}\right)$ and those determined with Method\#1 $\left(C_{j}^{\prime \prime}\right)$ for 9-14 August 2011, 11-12 October 2011, and 8-9 February 2012, are shown in Table 7. Lower discrepancies are observed in channels 1020, 675 and $870 \mathrm{~nm}$. However, only differences in $1020 \mathrm{~nm}$ are within the limit of instrumental precision of $\pm 0.01-0.02$. Discrepancies are significantly higher for the rest of channels, up to 0.07 for $500 \mathrm{~m}$ central wavelength channel.

The previous results highlight the lower accuracy showed by Method\#3, below the precision required to make comparable daytime and nighttime measurements. These discrepancies might be caused by a sum of contributions: (1) the accuracy on $I_{0, j}$ due to the implementation of the ROLO model (with an expected systematic error $\varepsilon \geq 0.01$ ); (2) the calibration errors from the integrated sphere method to obtain $C_{j}$ 's ( $\varepsilon=0.03-0.05$ ); and (3) uncertainties associated to the determination of the solid angle $\Omega(\varepsilon=0.03-0.05)$. Since the first 
Table 6. Master sky calibration coefficients $C_{j}$ calculated using an integrating sphere and $C_{j}^{\prime \prime}$ obtained from $\kappa_{j}$ 's and solid angles previously determined, both in $\mathrm{W} \mathrm{m}^{-2} \mathrm{~nm}^{-1} \mathrm{DC}^{-1}$. The spectral relative variation between both coefficients $(\Delta$ rel in $\%)$ is included.

\begin{tabular}{ccccccc}
\hline Channel $(\mathrm{nm})$ & 1020 & 1640 & 870 & 675 & 500 & 440 \\
\hline $\mathrm{CE}-1 C_{j}$ & $1.16 \times 10^{-6}$ & $2.15 \times 10^{-7}$ & $8.95 \times 10^{-7}$ & $1.15 \times 10^{-6}$ & $2.02 \times 10^{-6}$ & $1.70 \times 10^{-6}$ \\
$\mathrm{CE}-1 C_{j}^{\prime \prime}$ & $1.19 \times 10^{-6}$ & $1.97 \times 10^{-7}$ & $8.42 \times 10^{-7}$ & $1.13 \times 10^{-6}$ & $1.51 \times 10^{-6}$ & $1.88 \times 10^{-6}$ \\
$\Delta$ rel & 2 & 8 & 6 & 3 & 25 & -10 \\
\hline
\end{tabular}

Table 7. Averaged $\tau_{\mathrm{a}}$ differences $\left(\overline{d_{1}}\right)$ for seven nights period (914 August 2011, 11-12 October 2011, and 9-10 February 2012) obtained with calibration Method\#1 and \#3 using CE-1 photometer data. $\overline{d_{2}}$ corresponds to $\tau_{\mathrm{a}}$ differences in the same time period between Method\#1 and \#3 assuming a solid angle reported by the manufacturer, $\Omega_{\text {ref }}=3.4 \times 10^{-4} \mathrm{sr}$.

\begin{tabular}{ccccccc}
\hline $\begin{array}{c}\text { Channel } \\
(\mathrm{nm})\end{array}$ & 1020 & 1640 & 870 & 675 & 500 & 440 \\
\hline$\overline{d_{1}}$ & -0.012 & 0.051 & 0.035 & 0.016 & 0.071 & 0.042 \\
$\mathrm{RMSE}$ & 0.013 & 0.053 & 0.037 & 0.017 & 0.074 & 0.044 \\
\hline$\overline{d_{2}}$ & 0.094 & 0.056 & 0.048 & 0.060 & -0.004 & 0.019 \\
$\mathrm{RMSE}$ & 0.095 & 0.057 & 0.050 & 0.062 & 0.004 & 0.020 \\
\hline
\end{tabular}

contribution also affects to Method\#1, it is necessary to increase the accuracy of the integrating sphere calibration as well as in the determination of $\Omega$ to improve the results in Method \#3.

To check the error on the last contribution we have used the solid angle value provided by the manufacturer $\left(\Omega_{\text {ref }}=3.4 \times 10^{-4} \mathrm{sr}\right)$ and the coefficients $C_{j}$ presented in Table 6. $\Omega_{\text {ref }}$ is the wavelength independent solid angle assumed by Berkoff et al. (2011) to obtain nocturnal $\tau_{\mathrm{a}}$ information. A new $\tau_{\mathrm{a}}$ comparison between Method\#1 and \#3 using $\Omega_{\text {ref }}$ is also presented in Table 7. It can be seen that differences obtained $\left(\overline{d_{2}}\right)$ are notably higher than $\overline{d_{1}}$ from Table 7 for 1020 and $675 \mathrm{~nm}$ channels, slightly higher for $870 \mathrm{~nm}$, similar for $1640 \mathrm{~nm}$, slightly lower for $440 \mathrm{~nm}$ and considerably lower for $500 \mathrm{~nm}$. These differences are higher than those reported by Berkoff et al. (2011). It might indicate that the actual solid angle used by Berkoff et al. (2011) was closer to the manufacturer's reported value. These discrepancies clearly indicate that $\tau_{\mathrm{a}}$ calculation is very sensitive to the methodology to estimate $\Omega$.

\subsection{Angström's exponent}

Angström values have been obtained with CE-1 for the same cases analysis as for $\tau_{\mathrm{a}}$ (9-14 August 2011, 11-12 October 2011, and 8-9 February 2012).

Nocturnal $\alpha$ values for CE- 1 are computed as the slope of the linear regression of $\ln \left(\tau_{\mathrm{a}}\right)$ versus $\ln (\lambda)$ using channels at $870,675,500$ and $440 \mathrm{~nm}$, as shown in Eq. (9). Mean daytime $\alpha$ sunset and sunrise values were extracted from
Table 8. Averaged values of $\tau_{\mathrm{a}}$ (in 440 channel), $\alpha$ (Angström exponent) and $\delta \alpha$ obtained in August and October 2011, case studies. Values are for SS (sunset), MR (moonrise), MS (moonset) and SR (sunrise).

\begin{tabular}{|c|c|c|c|c|}
\hline & & $\tau_{\mathrm{a}, 440}$ & $\alpha$ & $\delta \alpha$ \\
\hline \multirow{2}{*}{9 August } & SS & 0.41 & 0.19 & 0.04 \\
\hline & MR & 0.40 & 0.16 & 0.04 \\
\hline \multirow{4}{*}{10 August } & MS & 0.40 & 0.16 & - \\
\hline & SR & 0.32 & 0.12 & -0.03 \\
\hline & SS & 0.12 & 0.35 & 0.04 \\
\hline & MR & 0.14 & 0.33 & 0.23 \\
\hline \multirow{4}{*}{11 August } & MS & 0.18 & 0.29 & 0.14 \\
\hline & SR & 0.17 & 0.25 & 0.01 \\
\hline & SS & 0.19 & 0.25 & -0.01 \\
\hline & MR & 0.20 & 0.23 & 0.02 \\
\hline \multirow{4}{*}{12 August } & MS & 0.11 & 0.48 & 0.22 \\
\hline & SR & 0.01 & 0.46 & 0.14 \\
\hline & SS & 0.07 & 0.63 & 0.15 \\
\hline & MR & 0.09 & 0.44 & 0.08 \\
\hline \multirow{4}{*}{13 August } & MS & 0.09 & 0.56 & 0.17 \\
\hline & SR & 0.06 & 0.68 & 0.20 \\
\hline & SS & 0.07 & 0.63 & 0.16 \\
\hline & MR & 0.08 & 0.53 & 0.17 \\
\hline \multirow{3}{*}{14 August } & MS & 0.12 & 0.12 & 0.06 \\
\hline & SR & 0.15 & 0.24 & 0.02 \\
\hline & SS & 0.30 & 0.16 & 0.05 \\
\hline \multirow{2}{*}{11 October } & SS & 0.07 & 1.03 & 0.40 \\
\hline & MR & 0.07 & 1.19 & 0.25 \\
\hline \multirow{2}{*}{12 October } & MS & 0.07 & 0.91 & 0.23 \\
\hline & SR & 0.06 & 1.06 & 0.47 \\
\hline
\end{tabular}

AERONET database. Results for $\tau_{\mathrm{a}}$ at $440 \mathrm{~nm}, \alpha$ and $\delta \alpha$ are presented in Table 8 for the August and October 2011 events. In these tables, we have included the aerosol information extracted for the sunset (SS) and the moonrise (MR) as the average of the last $1-\mathrm{h}$ data measured during daytime and nighttime, respectively. Moreover, we have considered data corresponding to sunrise (SR) and moonrise (MR), as the first 1-h data of each day and night.

$\alpha$ data derived in the two case studies range from 0.1 to 1.2. The prevalence of low $\alpha$ values indicate the presence of 
large particles $(>1 \mu \mathrm{m})$ during the saharan dust outbreaks. Minimum values below 0.2 are obtained for the periods 910 August and 13-14 August, which coincide with two important saharan dust intrusions over Tenerife and a maximum $\tau_{\mathrm{a}}>0.4$ (9 August). According to Basart et al. (2009), $\alpha=0.6$ represents an appropriate threshold value of dust laden air masses influenced by other aerosols, while $\alpha \leq 0.3$ indicates the presence of pure desert dust. On the other hand, $\alpha>0.7$ are found in those days with relatively low dust concentrations $\left(\tau_{\mathrm{a}}<0.10\right)$ during the October case study, suggesting the presence of other aerosols. A good concordance between daytime and nocturnal $\alpha$ values is found.

Finally, regarding the averages of the spectral variation of alpha $(\delta \alpha)$ presented in Table 8 , we have obtained near zero or slightly negative $\delta \alpha$ values between -0.01 and 0.01 during the important dust intrusions starting on 11 August and 14 August. These results are consistent with the experimental values between -0.3 and 0.1 obtained by Basart et al. (2009) in case of coarse mode saharan aerosols. A stable period of $\delta \alpha$ between 0.2 and 0.3 was observed from moonset 11 August to moonrise 12 August, and from moonset $12 \mathrm{Au}$ gust to moonrise 13 August. For October event, higher $\delta \alpha$ values are retrieved, between 0.3 and 0.4 . The low $\tau_{\mathrm{a}}$ during this period (around 0.07 at $440 \mathrm{~nm}$ ) and the positive values of $\delta \alpha$ indicate the existence of a bimodal-size distribution (O'Neill et al., 2001; Eck et al., 1999). These $\delta \alpha$ usually occurs when accumulation and coarse mode aerosols appear well-mixed (Basart et al., 2009) while relatively high positive values indicate the dominance of fine fraction aerosols (Eck et al., 1999).

\section{Summary and conclusions}

In this paper, we have described the preliminary results obtained with the new lunar photometer CE-318U, specifically designed to perform nocturnal photometric measurements. We have presented a first calibration strategy for this instrument which encompasses three different methods. Basically, this strategy requires the determination of the CE-318U calibration coefficients or their transference from a master instrument. The first Method consists of the adaptation of the usual Langley-plot method to nocturnal measurements. It introduces significant modifications to the current methodology, incorporating a lunar irradiance model (ROLO) to determine the instrument calibration coefficients. This strategy has been tested and validated using two CE-318U prototypes (CE-1 and CE-2), reporting discrepancies within the limit of $\tau_{\mathrm{a}}$ accuracy of the instrument $( \pm 0.01-0.02)$. For CE-1, this calibration was applied in other time periods, demonstrating the stability of the calibration. Moreover, nocturnal and daytime $\tau_{\mathrm{a}}$ comparison using AERONET and PFR under low and stable $\tau_{\mathrm{a}}$ conditions on 12 October 2011, showed similar differences between AERONET/PFR, AERONET/CE-1 and PFR/CE-1, within the AERONET $\tau_{\mathrm{a}}$ accuracy. This compar- ison, against two independent reference instruments constitutes a valuable assessment of CE-318U performance.

Method\#2 consists of transferring the calibration coefficients from a master. Results showed very close $\tau_{\mathrm{a}}$ between the two lunar photometers, with differences below 0.004 .

Method\#3 is based on obtaining the sky calibration constants $\left(C_{j}\right.$ 's) using an integrating-sphere and then retrieving the calibration coefficients $\kappa_{j}$ 's once the solid angle $\Omega$ is calculated. The comparison between $\tau_{\mathrm{a}}$ obtained using Method\#3 and the Method\#1 shows significant $\tau_{\mathrm{a}}$ differences of 0.07 and 0.05 for 500 and $1064 \mathrm{~nm}$ channels, respectively. For the rest of channels differences are lower, below 0.05 , but higher than the limit of instrumental accuracy expected for this instrument $( \pm 0.01-0.02)$. Such high discrepancies might be caused by the sum of errors in $\tau_{\mathrm{a}}$ determination process using Method\#3: (1) moon irradiances from ROLO model; (2) integrated sphere method to derive $C_{j}$ 's; and (3) the methodology to calculate $\Omega$. Our study highlights the importance of accounting for a high-performance integrating sphere and an accurate determination of $\Omega$ to assure a good calibration following Method\#3.

Finally, the comparison between daytime and nocturnal $\alpha$ showed a good agreement between daytime and nighttime data. $\delta \alpha$ results are also in agreement with the expected values for different atmospheric conditions presented each night according to reference values reported in the literature.

The consistency of these results points to the capabilities of this new photometer to obtain aerosol properties at night. Since column aerosol optical properties from sunphotometers are limited to the day-light period, this information becomes an important limitation in polar regions. In addition, monitoring the diurnal variation of aerosols is important in many sites associated to sea-land breezes, mountainvalley regime or the diurnal variations of the boundary layer height. It is also important for detecting the sharp changes that dust intrusions may experience in term of hours. Some sites with particular climatology present frequent clouds in the morning, while clear skies occurs during the night, resulting in important observation periods reduction with classical sunphotometers. Nowadays, lidar techniques, as those used in MPLNET, operate in full-time continuous mode $(24 \mathrm{~h}$ a day/365 days a year) to detect qualitatively the atmospheric aerosol content and its vertical distribution. However, it is necessary to improve the lidar extinction-to-backscatter ratio using additional $\tau_{\mathrm{a}}$ information provided by lunarphotometers during nighttime. $\tau_{\mathrm{a}}$ and $\alpha$ determination during the night can be used for long-term and near real time aerosol/dust models validation, as well as for new satelliteborne sensors verification. For example, the EUMETSAT Infrared Atmospheric Sounding Interferometer (IASI) sensor provides $\tau_{\mathrm{a}}$ during the night (Klüser et al., 2012). So, validation of both model and satellite $\tau_{\mathrm{a}}$ could be expanded to night periods. Concerning operational aerosol observations, the last eruption of the volcano Eyjafjöll, in spring 2010, highlighted the weakness of the current monitoring of this 
type of aerosols and the importance of having a continuous observation system to support the aircraft navigation. The joint observations of lidar/ceilometers and lunar photometers at night could help to fill monitoring gaps existing today.

To conclude, CE-318U lunar photometers in operational networks could be used as complementary instruments to expand the column aerosol observation periods and to enhance the operational capability in the Aerosol Robotic Network (AERONET). However, the complexities inherent to the lunar irradiance pattern, make lunar photometry a difficult task compared to sun-photometry. Thus, despite the good results reported in this paper, it is necessary to design a more refined calibration procedure. Further developments should be oriented to develop a photometer capable of taking measurement during both daytime and nighttime. Concerning calibration, efforts should be paid to transfer direct-sun Langley calibration to moon observations.

Nevertheless, at the present state, lunar photometry is an attractive option to complete aerosol databases.

Acknowledgements. The authors wish to thank Cimel for providing the two prototypes used in this study as well as all the technical support. In addition, we wish to express special thanks to Stone, at the United States Geological Service (USGS) for helping to implement the ROLO model and provide wise counsel to this paper. The Aeronet sunphotometer at Izaña has been calibrated within AERONET-EUROPE TNA supported by the European Community - Research Infrastructure Action under the FP7 "Capacities" specific programme for Integrating Activities, ACTRIS Grant Agreement no. 262254. The GAW-PFR network for AOD at GAW Global observatories has been implemented by the World Optical Depth Research and Calibration Center (WORCC). We want to thank Wehrli for supporting quality control and quality assurance of GAW-PFR data and for personal communications in this paper. Finally, the authors would like to express their thanks to the security staff at Izaña Observatory for kindly supporting the night operation of the lunar instruments. The integrating sphere was provided by the Infrastructure project entitled RIMA: Instrumental para infraestructura de calibracin fotométrica (RIMA-LC), Ref. UNVA05-23-038 from the Atmospheric Optics Group (GOA) at the University of Valladolid. Finally, the authors would like to thank the anonymous reviewers for their constructive suggestions.

Edited by: O. Torres

\section{References}

Angström, A. K.: On the atmospheric transmission of sun radiation and on the dust in the air, Geogr. Ann.,12, 130-159, 1929.

Basart, S., Pérez, C., Cuevas, E., Baldasano, J. M., and Gobbi, G. P.: Aerosol characterization in Northern Africa, Northeastern Atlantic, Mediterranean Basin and Middle East from direct-sun AERONET observations, Atmos. Chem. Phys., 9, 8265-8282, doi:10.5194/acp-9-8265-2009, 2009.

Berkoff, T. A., Sorokin, M., Stone, T., Eck, T. F., Hoff, R., Welton, E., and Holben, B.: Nocturnal aerosol optical depth mea- surements with a small-aperture automated photometer using the moon as a light source, J. Atmos. Ocean. Tech., 8, 1297-1306, doi:10.1175/JTECH-D-10-05036.1, 2011.

Campbell, J. R., Hlavka, D. L., Welton, E. J., Flynn, C. J., Turner, D. D., Spinhirne, J. D., Scott, V. S., and Hwang, I. H.: Full-time, Eye-Safe Cloud and Aerosol Lidar Observation at Atmospheric Radiation Measurement Program Sites: Instrument and Data Processing, J. Atmos. Oceanic Technol., 19, 431-442, 2002.

Eck, T. F., Holben, B. N., Reid, J. S., Dubovik, O., Smirnov, A., O'neill, N. T., Slutsker, I., and Kinne, S.: Wavelength dependence of the optical depth of biomass burning, urban, and desert dust aerosols, J. Geophys. Res., 104, 31333-31349, 1999.

Guirado C., Ramos, R., de Frutos, Á., Berjón, A., Redondas, A., López, C., Cachorro, V., Cuevas, E., González, R., González, S., and Hernández, M.: Optical calibration facility at the Izaña Atmospheric Research Center, Opt. Pura Apl., 45, 57-62, 2012.

Herber, A., Thomason, L. W., Gernandt, H., Leiterer, U., Nagel, D., Schulz, K., Kaptur, J., Albrecht, T., and Notholt, J.: Continuous day and night aerosol optical depth observations in the Artic between 1991 and 1999, J. Geophys. Res., 107, 4097, doi:10.1029/2001JD000536, 2002.

Holben, B. N., Eck, T. F., Slutsker, I., Tanré, D., Buis, J. P., Setzer, A., Vermote, E., Reagan, J. A., Kaufman, Y. J., Nakajima, T., Lavenu, F., Jankowiak, I., and Smirnov A.: AERONET - A federated instrument network and data archive for aerosol characterization, Remote Sens. Environ., 66, 1-16, 1998.

IPCC: Intergovernmental Panel on Climate Change: Climate change 2007: The physical Science Basis, Cambridge University Press, UK, 2007.

Kaufman, Y. J., Gitelson, A., Karnieli, A., Ganor, E., and Fraser, R. S.: Size distribution and phase function of aerosol particles retrieved from sky brightness measurements, J. Geophy. Res.Atmos., 99, 10331-10356, 1994.

Kieffer, H. H. and Stone, T. C.: The spectral irradiance of the moon, Astronom. J., 129, 2887-2901, 2005.

Kim, D., Chin, M., Yu, H., Eck, T. F., Sinyuk, A., Smirnov, A., and Holben, B. N.: Dust optical properties over North Africa and Arabian Peninsula derived from the AERONET dataset, Atmos. Chem. Phys., 11, 10733-10741, doi:10.5194/acp-1110733-2011, 2011.

Klüser, L., Kleiber, P., Holzer-Popp, T., and Grassian, V. H.: Desert dust observation from space - Application of measured mineral component infrared extinction spectra, Atmos. Environ., 54, 419-427, 2012.

Li, Z., Blarel, L., Podvin, T., Goloub, P., Buis, J. P., and Morel, J. P.: Transferring the calibration of direct solar irradiance to diffusesky radiance measurements for Cimel sun-sky radiometers, Appl. Opt., 47, 1368-1377, 2008.

Meeus, J.: Astronomical Algorithms, Willmann-Bell Inc., 1st Edn., Richmond, Virginia, USA, 1991.

Nyeki, S., Halios, C. H., Baum, W., Eleftheriadis, K., Flentje, H., Gröbner, J., Vuilleumier, L., and Wehrli, C.: Ground-based aerosol optical depth trends at three high-altitude sites in Switzerland and southern Germany from 1995 to 2010, J. Geophys. Res., 117, D18202, doi:10.1029/2012JD017493, 2012.

O’Neill, N. T., Dubovik, O., and Eck, T. F.: A modified Angstrom coefficient for the characterization of sub-micron aerosols, App. Opt., 40, 2368-2375, 2001. 
Smirnov, A., Holben, B. N., Eck, T. F., Dubovick, O., and Slutsker, I.: Cloud screening and quality control algorithms for the AERONET database, Remote Sens. Environ., 73, 337-349, 2000.

Spinhirne, J. D., Rall, J. A. R., and Scott, V. S.: Compact Eye Safe Lidar Systems, Rev. Laser Eng., 23, 112-118, 1995.

Stohl, A. and Seibert, P.: Accuracy of trajectories as determined from the conservation of meteorological tracers, Q. J. Roy. Meteorol. Soc., 124, 1465-1484, 1998.

Stohl, A., Wotawa, G., Seibert, P., and Kromp-Kolb, H.: Interpolation errors in wind fields as a function of spatial and temporal resolution and their impact on different types of kinematic trajectories, J. Appl. Meteor., 34, 2149-2165, 1995.
Toledano, C., Cachorro, V. E., Berjón, A., de Frutos, A. M., Fuertes, D., González, R., Torres, B., Rodrigo, R., Bennouna, Y., Martín, L., and Guirado, C.: RIMA-AERONET network: longterm monitoring of aerosol properties, Opt. Pura Apl., 44, 629633, 2011.

Walker, J. H., Cromer, C. L., and McLean, J. T.: Calibration of passive remote observing optical and microwave instrumentation, in: Proc. SPIE - The International Soc. of Optical Engineering, Orlando, FL, USA, 3-5 April 1991, 1493, 22-230, 1991.

Wehrli, C.: Spectral Solar Irradiance Data, WMO ITD 149, Geneva, WMO, 1986.

Zhang, J., Reid, J. S., Miller, S. D., and Turk, F. J.: Strategy for studying nocturnal aerosol optical depth using artificial lights, Int. J. Remote Sens., 29, 4599-4613, 2008. 